\title{
HÁ UMA FELICIDADE PARA OS TEMPOS DIFÍCEIS(?) ${ }^{1}$
}

\author{
THERE'S A HAPPINESS FOR HARD TIMES(?)
}

\begin{abstract}
Alexandro Henrique Paixão
Resumo: Este artigo compreende que sobreviver implica incrementar e desenvolver nossa capacidade de envolvimento pessoal e com o outro, algo que pode nos deixar mais felizes e dispostos para enfrentar as adversidades e os perigos de uma pandemia. Nesse sentido, será debatido como tema central a necessidade de intimidade, que se desdobra analiticamente em dois pontos principais: primeiro, discute-se a ânsia em poetizar o mundo devastado por uma doença geradora de sofrimento psíquico e social; segundo, coloca-se em perspectiva a ideia de que em nossa época moderna o imperativo era sair à rua, enquanto a ordem nos dias atuais é ficar em casa, algo que tem intensificado demasiadamente nossa vida mental, carecendo esse assunto de reflexão à luz da sociologia e da psicanálise, aqui mobilizadas para se pensar pandemia e sobrevivência.
\end{abstract}

Palavras-chave: Intimidade e sobrevivência; encantamento na pandemia; estrutura de sentimento endêmica.

Abstract: This article understands that surviving implies increasing and developing our capacity for personal involvement and with each other, something that can make us happier and more willing to face the adversities and dangers of a pandemic. In this sense, the need for intimacy will be discussed here as a central theme, whose analytical unfolding will be two main points: first, the eagerness to reenchant the world devastated by a disease that generates psychic and social suffering is discussed; second, the idea is put into perspective that in our modern times the imperative was to go out on the streets, while the order today is to stay at home, something that has intensified our mental life too much, lacking this subject for reflection in the light of the sociology and psychoanalysis mobilized here to think pandemic and survival. Keywords: Intimacy and survival; pandemic enchantment; endemic structure of feeling

Para Bel e sua família e a todas e todos que perderam pessoas queridas.

As sublimes e encorajadoras palavras do título são de Valter Hugo Mãe, extraídas do seu livro As mais belas coisas do mundo, de 2019. Escolhi essa frase para abrir o meu artigo, adicionando-lhe uma interrogação, porque considero que essa pergunta a respeito da felicidade cabe neste momento de tamanha tristeza e indignação, tanto por conta de milhares de mortes ocasionadas pela Covid-19 quanto pela banalização da vida exibida por algumas de nossas autoridades.

São tempos demasiado difíceis, nos quais o imperativo parece ser a dor e a desilusão produzidas por um contexto torturante e incerto. Dor e desilusão persistentes, mas não determinantes, tanto que o convite é para olharmos para a sobrevivência e seu continuum, almejando sonhar com novos mundos. Porque sobreviver implica em continuidade.

Quem acredita nisso é o personagem de Hugo Mãe, um menino "magro e ainda pequeno", que muito cedo sofreu uma grande tristeza ao perder seus avós, pessoas muito especiais e que estavam entre as coisas mais belas do mundo. Foi esse menino que escreveu

\footnotetext{
${ }^{1}$ Este artigo é uma ampliação e adaptação de uma palestra, originalmente dirigida aos professores sindicalizados da Associação de Docentes da Unicamp, no dia 19 de maio de 2020, transmitido pelo Facebook da Associação (cf. https://www.facebook.com/watch/live/?v=529844527686132\&ref=watch_permalink). Acesso em: 01 de junho de 2020.

${ }^{2}$ Universidade Estadual de Campinas, Campinas, São Paulo, Brasil.
} 
sobre a beleza e que nos disse que havia uma felicidade para os tempos difíceis, parecidos com esse que estamos vivendo.

Por isso, neste início, estou dando a palavra a ele, imaginando que suas ideias e sentimentos encorajadores talvez possam nos consolar um pouco, afinal, desde o começo do ano de 2020 - e isso parece não ter fim - temos perdido e vamos perder ainda muitos avós e avôs, entre tantos outros milhares de pessoas de todas as idades, gêneros, raças e nacionalidades. São mulheres, homens, crianças, idosos, toda uma nação enlutada e que pode estar se perguntando se "há uma felicidade para os tempos difíceis" (HUGO MÃE, 2019, p. 35).

Na visão do narrador-criança essa felicidade é um fato e por meio dele podemos nos sustentar, bem como tentar aceitar que quando pessoas tão especiais, como os avós, ficam muito doentes, eles precisam ficar sossegados e morrer. Morrer é ficar sossegado. Sobreviver é uma agitação, é um constante "bulir" (HUGO MÃE, 2019, p. 18 e p. 21). Ao bulir poetizamos o mundo, porque "o encanto é a única cura possível para a inevitável tristeza” (HUGO MÃE, 2019, p. 12).

Mas é possível nos encantar em meio à desilusão e à melancolia do presente? É possível manter nossa vontade de viver e nossos desejos em meio às perdas de uma pandemia? São perguntas difíceis e sem uma resposta previsível, afinal, como é possível "mesmo com toda coisa ruim que acontece acontecendo" ficar feliz ou alegre? (GUIMARÃES ROSA, 2019, p. 86).

Quem carregava essa mesma inquietação era outro menino pequeno, Miguilim, um habitante lá do Mutum no "Campo Geral", numa morada "bonita", distante das terras ibéricas do personagem de Hugo Mãe. Ele fez o mesmo questionamento sobre a felicidade em tempos difíceis, embora tenha respondido cismado que essa "repentina esperança" era uma "loucura" (GUIMARÃES ROSA, 2019, p. 87). Loucura ou não, a felicidade coexistia com a dor e a morte, e pensar nisso produzia um grande medo em Miguilim, embora ele imaginasse que determinada verdade havia nisso tudo, sendo necessário reagir através do pensamento. Não importava se esse pensar estava carregado de muitas amarguras ou certezas de que coisas ainda mais ruins estavam por suceder (GUIMARÃES ROSA, 2019, p. 45). Pensar era imperativo, mesmo a alma de Miguilim temendo gritos (GUIMARÃES ROSA, 2019, p. 50).

Gritos que talvez nos povoem agora e ecoem ideias dissonantes que ainda não encontram um lugar para se firmar, porque o sofrimento atroz nos desequilibra emocional e fisicamente, bagunça o tempo e o espaço e deixa uma sensação de que certas coisas não cabem mais, porque tudo fica tarde (GUIMARÃES ROSA, 2019, p. 51). Mas ainda assim cabe pensar, tentar fazer perguntas e escolhas e tomar algumas decisões. Uma decisão como a de seguir com esta prosa sobre a vontade de viver em um mundo endêmico e aniquilador, separando agora outra referência literária para prosseguir.

É um excerto que considero oportuno para adentrarmos no debate da vontade de viver e do desejo de encantar o mundo em meio a uma pandemia:

Havia vários anos que a cólera indiana demonstrava crescente tendência de se propagar e de migrar de um país ao outro. Nascida nos pântanos quentes do delta do Ganges, fomentada pelo hálito mefítico desse mundo antediluviano de ilhas exuberantes, inúteis, inabitáveis, em cujos emaranhados bambuzais espreita o tigre, a praga assolara por muito tempo e com inusitada violência todo o Hindustão, para depois espalhar-se em direção ao leste, até a China, e pelo oeste, rumo ao Afeganistão e à Pérsia. Seguindo as estradas principais das grandes caravanas, levara o seu terror até Astracã e até a própria Moscou. Mas, enquanto a Europa ainda receava que o fantasma pudesse invadi-la dali, por terra, surgira ele quase ao mesmo tempo em diversos portos mediterrâneos, aonde embarcações de comerciantes sírios o haviam levado. Erguera a sua cabeça em Toulon e Málaga. Mostrara a sua carranca amiudadamente em Palermo e Nápoles, e parecia não 
querer afastar-se de toda a região da Calábria e da Apúlia. O norte da península escapara inicialmente. Por meados de maio deste ano, porém, os horripilantes vibriões foram encontrados num e no mesmo dia nos descarnados e enegrecidos cadáveres de um tripulante de um navio e de uma vendedora de legumes. Os casos foram ocultados, mas uma semana depois já havia dez, havia vinte, trinta, e isso em zonas diferentes. Um austríaco do interior, que passara alguns dias de férias em Veneza, faleceu logo depois de seu regresso à sua cidadezinha natal, e os sintomas não deixaram dúvidas... Oitenta por cento das pessoas atingidas morriam de modo pavoroso, porquanto o mal se manifestava com extrema ferocidade... Mas o medo de um prejuízo geral... o receio de enormes perdas que, no caso de um pânico ou de um descrédito da cidade, sofreriam os hotéis, os lojistas e todos os ramos da exploração do turismo... Em virtude disso, as autoridades aferravam-se obstinadamente à sua política de silêncio, desmentindo todo e qualquer boato. $\mathrm{O}$ diretor do Departamento de Saúde da cidade, homem de grandes méritos, demitirase, indignado, de seu posto e fora substituído, convenientemente, por uma personalidade mais dócil. O povo sabia dessas ocorrências, e a corrupção da alta sociedade, em combinação com a insegurança reinante devido à situação anormal que o progresso da mortalidade produzia... certos estímulos obscuros, antissociais, que se manifestavam sob o aspecto de intemperança, despudor e sempre crescente criminalidade... Em face de tudo isso... A quarentena deverá ser decretada dentro de poucos dias, no máximo.

O trecho em questão, apesar de parecer ter sido extraído de alguma literatura ou narrativa dos nossos dias, dadas as semelhanças com a situação que estamos vivendo frente à pandemia Covid-19, foi retirado do conto A morte em Veneza, de 1912, de Thomas Mann (2015, p. 7274), e vai nos ajudar a continuar com o tema do encantamento e da vontade de viver em meio à quarentena decretada há mais de 100 dias.

O que Thomas Mann transpõe neste excerto de sua prosa ficcional é um relato verídico de uma pandemia que se iniciou no sul da Ásia, no Hindustão, na Índia, alastrou-se pela China, Rússia, cidades da França, Espanha e Itália, especialmente na cidade de Veneza, desenhando um verdadeiro mapa da destruição do chamado cólera indiano, que percorreu o mundo entre o final do século XIX e início do XX, através de cidades portuárias - parece-me, inclusive, que os últimos focos do cólera indiano datam de 1912, que é o mesmo ano de publicação do conto.

Thomas Mann agrupou suas causas e consequências nefastas principalmente no parágrafo supracitado de A morte em Veneza, retendo nessas poucas linhas o vórtice de toda uma pandemia que impactou a vida doméstica, pública e comercial de Veneza e causou milhares de mortes pelo mundo, dentre elas a de seu personagem de ficção, Gustav Aschenbach.

Mas quem conhece esse conto sublime ou assistiu ao magnífico filme de Luchino Visconti, de 1971, sabe que A morte em Veneza não é uma narrativa apenas sobre a morte causada por essa pandemia que assolou Veneza num tempo e espaço específicos, mas uma história sobre a aventura dos nossos sentimentos e todas as investidas possíveis para reencantar o mundo pela "esfera erótica”. É o narrador que nos confirma isso, ao exclamar: “... que Eros se coloque a nosso lado e se arrogue o direito de nos guiar..." (MANN, 2015, p. 80).

Mas seria possível se guiar pela figura de Eros e "poetizar o mundo" num momento de pandemia, morte e quarentena, como fez Thomas Mann em seu conto, numa alusão a Fedro, de Platão, e seu discurso sobre o amor? Insisto na questão: por que tratar dessa "estrutura de sentimento" (WILLIAMS, 2011, p. 69) relacionada às nossas paixões e à vontade de viver, nesse contexto em que milhares de vidas estão desaparecendo e estamos mergulhados em um medo atroz e inseguros quanto a sermos a próxima vítima? Cabe pensar em nossos desejos, a partir do conto de Thomas Mann, sem que o sofrimento, a dor ou o luto sejam banalizados? 
Não seria mais acertado discutir a ansiedade provocada pelos perigos externos e sobre como atenuá-la, do que tratar daquilo que provoca um conjunto de estímulos e intensificações nervosas, como os nossos desejos?

$\mathrm{Na}$ verdade, é justamente por conta desses sofrimentos que eu gostaria de falar das paixões eróticas, só que substituindo esse termo por "paixões amorosas", como uma espécie de alimento vivo que contém vida e morte, embora minha ênfase sejam as sementes de vida: "Há ideias e formas de pensar que encerram sementes de vida e há outras, talvez, profundamente arraigadas em nossas mentes, que encerram sementes de morte" (WILLIAMS, 1969, p. 346). Insistirei nas sementes de vida e na dinâmica dos afetos que emerge disso, reconhecendo que necessitamos de uma organização psíquica para enfrentar essa estrutura de sentimento endêmica que tem se constituído a cada instante e parece fundar outra cultura. ${ }^{3}$

Permanece a morte. Escolho falar da vida, não para me afastar das tragédias, perdas e derrotas que nos assolam, mas para retomar o fôlego e escolher um ponto de partida para o cuidado, relacionado à esfera íntima da vida cotidiana.

Feitas essas escolhas, para prosseguir nesse tema dos desejos quero trazer para o debate aquilo que Freud escreveu sobre Schopenhauer em "Extrato de $O$ mundo como vontade e ideia". Segundo ele, as paixões evocam a vontade de viver, e, consequentemente, concentram em si a totalidade dos nossos desejos (FREUD, 1996, Vol. XIX, p. 252). Mas, se, por um lado, a vontade de viver se torna uma aspiração essencial em tempos de pandemia, por outro, aflora com essa vontade uma multidão de anseios, tais como: querer encontrar familiares e amigos; festejar; apaixonar-se; comprar coisas; viajar; passear de carro ou no parque; jogar futebol; fazer ginástica; ficar saudável; deixar o interior da casa e se expor na rua, algo possivelmente arriscado num contexto de crise sanitária.

Então, será que cabe deixar Eros nos guiar? E guiar para onde? Eu diria que para a direção de uma "luz mortiça de uma esfera irreal", para usar uma expressão extraída de uma das passagens de Max Weber sobre a esfera erótica (WEBER, 2010, p. 242). "Irreal", porque a pandemia alterou, decisivamente, na esfera da vida cotidiana a medida do tempo (faltam previsões e escalas) e do espaço (por conta das vivências on-line), nos fazendo "tatear a imensidão", para usar outra expressão de Thomas Mann (2015, p. 27). Uma imensidão que evoca a imago de um vazio, que muitos de nós têm preenchido com notícias diárias de jornais, TVs, rádios, internet, as quais, ao final de uma semana, parecem não formar um todo, uma unidade de pensamento e ação. São informações, números e estatísticas pouco precisos, coloridos por imagens de caos, destruição e dor, mas sem chances de reparação, devido à velocidade em que a ordem das coisas vai acontecendo e mudando diante dos nossos olhos, provocando uma intensificação da vida mental. ${ }^{4}$

Multiplicam-se com isso queixas sobre insônia, hipocondria, fobias, choro excessivo, dores de cabeça, tontura, raiva, medo do colapso, luto, melancolia, depressão, enfim, um

\footnotetext{
${ }^{3}$ Depois de iniciar a produção deste texto na companhia de Williams e dos outros autores que aqui estão sendo mencionados, a socióloga e amiga Mariana Chaguri me apresentou um artigo de jornal que considerei muito acertado sobre essa questão da estrutura de sentimento endêmica; decidi destacá-lo aqui: "The Coronavirus is rewriting our imaginations", de autoria de Kim Stanley Robinson (https://www.newyorker.com/culture/annals-of-inquiry/thecoronavirus-and-our-future - acesso em 01 de junho de 2020), faz referência ao termo "estrutura de sentimento" de Raymond Williams para afirmar que cada período histórico tem sua própria estrutura de sentimento, o que permite afirmar que estamos numa nova estrutura, produzida pela pandemia: "It was a change in the way we were looking at things, and it is still ongoing. The virus is rewriting our imaginations. What felt impossible has become thinkable. We're getting a different sense of our place in history. We know we're entering a new world, a new era. We seem to be learning our way into a new structure of feeling" (ROBINSON, 2020, p. 02).

${ }^{4}$ Tamanha é sua velocidade que partes deste texto (como dito inicialmente, uma palestra), foi produzido para pensar a quarentena, uma realidade cada vez menos marcante com as medidas governamentais de relaxamento do isolamento social. Mas ainda assim cabe tratarmos desse assunto, pois há muitas pessoas "nervosas" com as saídas às ruas.
} 
verdadeiro mal-estar psíquico-somático que, num primeiro momento, parece algo conhecido e controlado, afinal crises são constitutivas de nossa existência, logo, temos alguma experiência para enfrentá-las. Só que esses sintomas, distúrbios, falhas não estão acontecendo sob a ordem mesma das coisas, eles se inscrevem numa outra "moldura", a da quarentena provocada pela pandemia. Ela tem uma organização e dinâmica próprias nessa nova estrutura de sentimento endêmica que repete dores antigas ao mesmo tempo em que se processam os novos sofrimentos no âmago de uma atmosfera de isolamento. Porque antes, em nossa modernidade, era a saída às ruas das grandes cidades que intensificava a vida do espírito, por conta dos milhares de estímulos e excitações da vida moderna, conforme nos apresentou Georg Simmel, em 1903: “O fundamento psicológico sobre o qual se eleva o tipo das individualidades da cidade grande é a intensificação da vida nervosa, que resulta da mudança rápida e ininterrupta de impressões interiores e exteriores" (SIMMEL, 2005, p. 578). Hoje, aproximadamente 120 anos depois, ficar em casa nas grandes cidades marca um novo tempo e um novo dispêndio social e psíquico que está intensificando nossas vidas e demandando atenção.

Assim como naquela época de modernização Simmel buscou respostas sociológicas e psíquicas nos conteúdos individuais e supra-individuais da vida (SIMMEL, 2005, p. 577), vou me apoiar nele e buscar na esfera da nossa intimidade determinada explicação para certos e novos desafios interiores e exteriores dos dias atuais.

E quando há algo novo, as reações mentais podem ser muitas, conforme nos lembra outra vez Freud, na abertura de seu ensaio "Resistências à Psicanálise", de 1925. O novo, segundo ele, seria uma fonte de desprazer, devido tanto ao "dispêndio psíquico que exige", quanto às incertezas e às expectativas produzidas frente ao desconhecido. ${ }^{5}$ Pode-se aventar que ele é uma fonte inesgotável de ansiedade, tão infinita quanto nossos desejos. Existiria, portanto, uma similitude entre os sentimentos novos (desprazer) e os desejos (prazer), evocando o que Freud diz quando lemos seu ensaio "Além do princípio do prazer" (FREUD, 1996, Vol. XVIII) onde nos é sugerido que nosso aparelho mental existe e reage para diminuir a dor e o desprazer. $\mathrm{O}$ convite é para refletirmos sobre nossos desejos neste momento e tentar prová-los na realidade por meio do pensamento, recordando o que Miguilim nos ofereceu no início desta discussão.

Porque a atividade do pensar nos ajuda a circunscrever ou delimitar os nossos desejos, propiciando um ambiente mais protegido frente aos perigos externos e internos (FREUD, 1996, Vol. XX, p. 87). Então, não se trata de negar os desejos e as paixões, mas avaliar se aquilo que ansiamos em tempos de pandemia é seguro para as nossas vidas ou se esses desejos enriquecem nossa vontade necessária de viver, permitindo vivenciar a satisfação e não somente o desprazer. Com isso, estou sugerindo que quanto maior o relacionamento íntimo, maior é a organização psíquica e menores as possibilidades de rebaixar o processo de satisfação a um sintoma, como o medo ou a ansiedade (FREUD, 1996, Vol. XX, p. 98). Em outras palavras, o desenvolvimento da intimidade diminui a tensão e a angústia, e, consequentemente, restringe o aumento da ansiedade e do medo.

E o que o mais poderia enriquecer nossa vontade de viver nestes tempos tão difíceis? Sou levado a acreditar, pela vivência como professor, pesquisador e psicoterapeuta, que nesse momento de quarentena precisamos investir em nossa intimidade e desenvolvê-la pela seguinte razão: nossas paixões nascem num ambiente íntimo, lá nos primeiros momentos de nossa vida, junto com nossas mães, pais ou cuidadores. É ali que despertamos para a vida, para a vontade de viver, e é exatamente nesse lugar que estamos agora, reservados em nossas casas com nossos pais, mães, filhos e avós, nossas famílias. Se outrora na modernidade as correntes e os estímulos

\footnotetext{
${ }^{5}$ Nas palavras do autor: "A fonte desse desprazer é a exigência feita à mente por algo que é novo, o dispêndio psíquico que ela exige, a incerteza alçada até a ansiosa expectativa que ela traz consigo" (FREUD, 1996, Vol. XIX, p. 241 - grifo do autor).
} 
externos provocados pelas saídas às ruas das grandes cidades exigiam a criação de artifícios protetores contra o desenraizamento inevitável (SIMMEL, 2005, p. 578), hoje em dia, fazendo uma transposição rápida do extraordinário raciocínio de Simmel, caberia pensar que são necessários novos dispositivos psíquicos para proporcionar o enraizamento na vida íntima cotidiana e garantir a sobrevivência. Por isso, faço uma aposta na importância de incrementarmos nossa intimidade, com o aporte daquilo que Freud nos legou ao dizer que é fácil construir um "escudo protetor... no tocante a estímulos externos". Difícil é lidar com as "exigências instintuais internas", de onde disparam nossos desejos e se iniciam processos excitatórios e de repressão, em função das nossas inúmeras tentativas e investimentos nos processos de satisfação (FREUD, 1996, Vol. XX, p. 95 e p. 98).

Feitas essas considerações, temos uma hipótese a perseguir para terminar: nossa intimidade parece estar inscrita dentro de uma outra estrutura de sentimento com características endêmicas, produzindo uma sensibilidade nova devido aos riscos que se corre ao tentar sair à rua e deixar o interior da casa, espaço por excelência da intimidade (interpessoal e intrapsíquica). Ocorre a busca incessante pela satisfação, rebaixando a proteção, a estabilidade, a confiança em si mesmo e no outro, ameaçando a sobrevivência necessária em tempos de pandemia.

\section{Processos de satisfação}

É justamente em nossa residência que devemos ficar e é onde podemos desenvolver as interações e comunicações mais íntimas, por meio de diálogos enriquecidos, conversas simples ou trocas de mensagens com aqueles que estão presentes ou não - refiro-me aos que temos encontrado remotamente, graças a "Meet", ao "Whatsapp", aos "e-mails", por motivos de estudos, trabalho ou bate-papo trivial; também podemos interagir intimamente por meio do serviço doméstico compartilhado ou pelas horas das refeições - comer em casa é sempre prazeroso, tanto para quem prepara a comida quanto para aqueles que a desfrutam e depois ajudam a arrumar a cozinha e secar a louça; ficamos mais íntimos no cuidado do corpo e da mente pelos exercícios físicos e nos investimentos em nossa saúde mental; pelo cultivo do espírito através da leitura, do entretenimento fílmico, dos jogos, das brincadeiras; enfim, tudo isso e muito mais pode propiciar intimidade ou incrementar nossa capacidade de envolvimento pessoal e mútuo com os familiares, almejando proporcionar alguma segurança, e, consequentemente, confiança e estabilidade. Essa estabilidade, em grande ou pequena medida, até existia antes da quarentena e todos podemos mobilizá-la ou recuperá-la para nos ajudar a ficar mais envolvidos e íntimos com a gente mesmo e com as nossas famílias.

E é sempre bom lembrar que há famílias de todos os tipos, com muitas ou poucas pessoas, com companheiros de estimação e até famílias de uma pessoa só. Aliás, mesmo os sujeitos mais solitários podem ficar íntimos ou envolver-se consigo mesmos na reserva de seus lares. Essa tarefa depende em grande parte de nós, adultos, embora fique sempre a questão de quem ajudará ou cuidará dos adultos nos momentos mais difíceis. Se não houver outro adulto para dividir o peso dos desafios e dilemas, necessitamos nos apoiar em nós mesmos e naqueles em quem confiamos, que neste momento podem estar próximos ou distantes; pode ser o amigo ou amiga do Whatsapp ou do Facebook, pode ser o chefe ou o professor, ou mesmo a criança, o cachorro, o gato e até o bicho de pelúcia, ${ }^{6}$ pois os "objetos transicionais" também ajudam (WINNICOTT, 1975, p. 13-30). Ajuda também reconhecer em nossas famílias os que estão mais disponíveis, verificar se podemos demandá-los e se é possível depois liberá-los para se recuperarem a fim de retomarem a posteriori sua posição de suporte - sempre existe alguém com maior ou menor

\footnotetext{
${ }^{6}$ Convido à leitura do conto de Victor Hugo, O Ogro da Rússia (2012).
} 
disponibilidade entre nós. Não precisamos viver nada sozinhos e podemos sempre buscar acolhimento onde ele estiver. Mas é bom reconhecer as nossas reservas emocionais, as experiências ricas e os recursos que tínhamos antes de tudo começar. Nossa mente criativa reside nisso também, digo, em reconhecer que guardamos sabedorias em nossos "almoxarifados" pessoais para reforçar o amor, a confiança e a perseverança, o que proporciona densidade e ancoragem para os "maus pensamentos, tentações, desejos". ${ }^{7}$ O convite é sempre enfatizar o cuidado; felizmente, escuto de todos que me cercam ou me dão notícias das formas mais variadas que o cuidar está em andamento e que estamos conseguindo construir uma espécie de assistência à saúde física e mental em nossas residências.

Aliás, há um importante texto de Donald Winnicott sobre isso, chamado "Assistência residencial como terapia", de 1970, no qual o autor destaca cinco características essenciais para a construção de uma estabilidade íntima, sendo necessário: $1^{\circ}$ ) confiabilidade intrínseca, porque a imprevisibilidade e as frustrações terão sempre presença; $2^{\circ}$ ) segurança física e emocional; $3^{\circ}$ ) planejamento e a divisão de tarefas; $4^{\circ}$ ) gratidão, porque o "muito obrigado" incrementa a dinâmica dos afetos e exercita a humildade e o bom-humor; e, por fim, $5^{\circ}$ ) sobrevivência, porque nossa principal tarefa em tempos de crise é sobreviver (WINNICOTT, 1999, p. 254-257). Sobrevivência significa não só reconhecer que continuaremos vivos depois de tudo isso, mas que foi possível, apesar das dificuldades, tristezas e perdas, manter nossa humanidade, reservando na memória aquele sentimento de que os "tempos são difíceis, mas não impossíveis", 8 só que acrescentando mais um termo: tempos difíceis, mas não impossíveis, porque existe uma felicidade para eles, já diziam nossas personalidades-crianças no início deste texto.

"Não é apenas o alimento ou teto que conta, e nem mesmo o lazer proporcionado, embora essas coisas sejam, sem dúvida, bastante importantes" (WINNICOTT, 1999, p. 56-57). Mas expressar diretamente nossos afetos e apaziguar as frustrações, diminuindo o autocontrole, a culpa, a rigidez e a sobrecarga de tarefas e deveres ligados à vida doméstica, ao trabalho ou estudo é importante também. Tentar criar, na verdade, oportunidades para o planejamento criativo e mais leve dessas atividades; compartilhar as responsabilidades, mas também os medos e as apreensões; e buscar avaliar quais são os tipos de necessidades físicas e emocionais do presente, discriminando, se for possível, o que é localizado, agudo ou emergencial, buscando se preciso ajuda profissional; tudo isso e muito mais pode nos ajudar a estabilizar nossa condição humana nesse novo mundo cada vez mais aniquilador. Em síntese, esses e outros pontos podem ser "uma nova oportunidade para conviver e harmonizar-se com um mundo duro e difícil" (WINNICOTT, 1999, p. 54-58), com urgências e muitas exigências.

As exigências são tantas que espero que vocês recebam isso tudo não como mais uma tarefa árdua frente a tantas outras que estão desempenhando nesta quarentena, afinal, os desafios têm sido muitos, ainda mais num contexto de amplas demandas domésticas e aprofundamento das desigualdades, face ao gênero, à raça, à classe, à idade, às nacionalidades. E por falar em demandas e desigualdades, não estou desconsiderando o fato de que a intimidade, neste momento de isolamento social, pode produzir também um envolvimento agressivo, violento, voraz, entre os entes familiares. É sempre bom lembrar que o amor e o ódio são elementos constitutivos de todas as relações humanas e que o ódio, consequentemente, a agressividade, a voracidade ou as investidas violentas, como as invasões e os ataques, são

\footnotetext{
${ }^{7}$ Faço essas ponderações lendo Adélia Prado, especialmente quando confidencia: "Tinha vantagens não saber do inconsciente, vinha tudo de fora, maus pensamentos, tentações, desejos. Contudo, ficar sabendo foi melhor, estou mais densa, tenho âncora, paro em pé por mais tempo. De vez em quando ainda fico oca, o corpo hostil e Deus bravo. Passo logo. Como um pato sabe nadar sem saber, sei sabendo que, se for preciso, na hora $\mathrm{H}$ nado com desenvoltura. Guardo sabedorias no almoxarifado" (PRADO, 2005, p. 57).

${ }^{8}$ Para citar uma expressão cunhada pela Profa. Dra. Nora Krawczyk, docente da Faculdade de Educação da UNICAMP.
} 
reações à frustração ou ao desejo malsucedido. Mas é reconhecendo tudo isso, e também que o medo pode gerar agressão, que insisto na necessidade de intimidade, no envolvimento pessoal e mútuo, que é o contrário do abandono de nós mesmos, consequentemente, da nossa responsabilidade, do nosso amor próprio e dedicado aos outros.

Winnicott, vocês já devem ter percebido, é quem estou seguindo em todos esses momentos, e mais particularmente agora em seu ensaio "Agressão e suas raízes", de 1939, inclusive escrito para os professores, no qual ele destaca que "a agressão está sempre ligada, desta maneira, ao estabelecimento de uma distinção entre o que é e o que não é o eu" (WINNICOTT, 1999, p. 104). O que significa que experimentar uma relação mais íntima consigo mesmo e com o outro envolve sempre uma relação de amor e agressividade, sendo isso base do sentimento de identidade. O que implica afirmar, dentro de uma matriz originalmente freudiana, que identidade envolve uma "experiência de satisfação", em que o desejo pressupõe uma atração positiva do objeto desejado (FREUD, 1996, Vol. I, p. 383).

Com isso, estamos de volta ao tema dos nossos desejos (as paixões amorosas e a vontade de viver) e com a intenção de reforçar a necessidade de intimidade como uma substância necessária não só para nos fortalecer frente aos desafios da quarentena e do porvir, mas para promover a estabilidade emocional e níveis variados de satisfação.

Aliás, abro um pequeno parêntese para destacar que quando me refiro a satisfação, não estou pensando naquele tipo de "satisfação narcísica", que visa lisonjear o amor próprio e estimular o sentimento de onipotência, a partir da qual se "é melhor que outras pessoas, porque [se] é especialmente limpo ou especialmente consciencioso", conforme fazem os tipos mais paranoicos em suas construções delirantes de sabedoria e higiene (FREUD, 1996, Vol. XX, p. 103 interpolação por minha conta), algo, aliás, que ganha bastante força em tempos de pandemia e frente à necessidade de medidas austeras de controle sanitário. Mas não se trata disso aqui: a satisfação que quero enfatizar é aquela geradora de um ambiente mais confiante, seguro e protegido para todos em situação familiar, algo promovido pela capacidade de envolvimento íntimo.

Fecho o parêntese e concluo, em termos psicanalíticos, que dessa forma teremos proporcionado um "novo ambiente", porque é a partir dessas coisas mencionadas que se poderá desenvolver nossa capacidade de envolvimento pessoal, e em torno disso se poderá germinar um "ambiente suficientemente bom", necessário para conseguirmos sobreviver e enfrentar perigos internos e externos.

Intimidade é sinônimo de vida interior enriquecida, o que aprimora a vida exterior. Intimidade é uma "unidade básica", uma necessidade absoluta de preservar os modos de funcionamento indispensáveis à sobrevivência (LITTLE, 1994, p. 112). E já que estamos distanciados e/ou isolados, parcialmente ou integralmente em nossas casas e num momento imprevisível, podemos investir bastante nisso, isto é, em nossa capacidade de envolvimento com a gente mesmo (relação intrapsíquica) e com aqueles que estão participando da quarentena conosco (relação interpessoal), algo que poderá incrementar as interações mútuas (relação social) em todos os níveis e até quem sabe mesmo alcançar maneiras mais democráticas de conviver, embora isso seja outro assunto. ${ }^{9}$

Dando voz, uma última vez, a Winnicott, em seu artigo intitulado "O desenvolvimento da capacidade de envolvimento", de 1962, notamos que ele considera que envolvimento implica desenvolvimento pessoal e se relaciona com o senso de responsabilidade que devemos ter frente a nós mesmos, ao outro e aos nossos desejos. Implica preocupar-se ou importar-se mutuamente e aceitar isso como um desígnio da responsabilidade. O envolvimento é a base da vida familiar, e que

\footnotetext{
${ }^{9}$ Sobre o caráter mais democrático da esfera íntima, repasso, a título de ilustração, aquilo que Anthony Giddens ressalta sobre a intimidade ser uma realização emocional que implica uma democratização dentro do domínio interpessoal (GIDDENS, 1993, p. 11).
} 
fique evidente que quando me refiro à família, estou pensando em todos os tipos de famílias e considerando essa unidade social como vital. Tamanha é sua vitalidade, que ela é necessária para aqueles que estão em casa, em quarentena, e também para aqueles que precisam sair de casa para trabalhar, mas que podem sonhar em voltar para a intimidade do lar que deixam todos os dias.

Intimidade é uma questão de saúde e de sobrevivência, pois, uma vez criada, ajuda a construir a unidade do nosso ego e algumas de suas funções, como a confiança, a estabilidade emocional e a capacidade de se sustentar e também de fantasiar, sonhar e desejar. É importante destacar que estou simplificando essa discussão sobre o processo maturativo, mas Winnicott apresenta essas formulações de forma bastante elaborada, razão pela qual convido todos a lerem seus trabalhos.

Em síntese, quanto mais íntimos de nós mesmos, mais responsáveis e protegidos ficamos. Quanto menor a intimidade, menor o envolvimento, mais difícil é enfrentar os desafios de uma situação de quarentena. Isso porque, segundo o psicanalista inglês, a falta de envolvimento pessoal e mútuo produz "angústias cruas", ou, podemos dizer que ficamos como se estivéssemos em carne viva, logo, indisponíveis para enfrentar nossa realidade tão calamitosa e necessitada de íntima perseverança.

Pensando nisso, na necessidade de intimidade, para finalizar de fato, apresento o trecho de um livro de Primo Levi, chamado A trégua, onde ele conta como uma criança que nasceu em Auschwitz sobreviveu alguns anos dentro daquele campo de extermínio:

Hurbinek era... um filho de Auschwitz. Aparentava três anos aproximadamente, ninguém sabia nada a seu respeito, não sabia falar e não tinha nome: aquele curioso nome, Hurbinek, fora-lhe atribuído por nós, talvez por umas mulheres, que interpretaram com aquelas sílabas uma das vozes inarticuladas que o pequeno emitia, de quando em quando... As palavras que lhe faltavam, que ninguém se preocupava de ensinar-lhe... Ninguém, salvo Henek... [ele] era meu vizinho de cama, um robusto e vigoroso rapaz húngaro de quinze anos. Henek passava metade de seus dias junto ao catre de Hurbinek. Era maternal mais do que paternal... Hurbinek aprenderia a falar com Henek; certamente mais do que com as meninas polonesas, demasiado doces e demasiado fúteis, que o embriagavam de carícias e de beijos, mas evitavam-lhe a intimidade (LEVI, 2010, p. 19-20 interpolação e grifo meus).

Hurbinek não sobreviveu a Auschwitz, mas enquanto viveu, apesar de sua existência bastante precária, conseguiu se comunicar, embora não graças às carícias e aos beijos de alguns, mas à capacidade de envolvimento íntimo que um garoto de quinze anos proporcionou àquela criança. Primo nos diz mais algumas palavras sobre isso:

Henek... tranquilo e obstinado, sentava-se junto [ao pequeno], imune à autoridade triste que dele emanava; levava-lhe a comida, ajustava-lhe as cobertas, limpava-o com mãos habilidosas, desprovidas de repugnância; e falava-lhe, naturalmente, em húngaro, com voz lenta e paciente (LEVI, 2010, p. 20 - interpolação por minha conta).

Ao ler emocionado esse último excerto sou impulsionado a pensar que, com essas duas outras crianças, temos o testemunho de que a intimidade é a responsável por produzir em nós a vontade de viver, mesmo em condições tão adversas. É graças a ela que podemos encontrar alguma felicidade para os tempos difíceis, conforme nos ensinaram outros dois meninos no início desta prosa. E quando há tantas perdas e incertezas, em meio a um contexto aniquilador e imprevisível, tentar incrementar nossa capacidade de envolvimento íntimo é um sinal 
importante de confiança, perseverança, sobrevivência e felicidade, afinal, alguém disse que a felicidade é a experiência de todas as infelicidades. ${ }^{10}$

\section{Referências}

FREUD, Sigmund. Além do princípio do prazer (1920). In: FREUD, Sigmund. Além do princípio do prazer, psicologia de grupo e outros trabalhos (1920-1922). Rio de Janeiro: Imago, 1996, vol. XIX.

FREUD, Sigmund. As resistências à psicanálise (1925 [1924]) e Apêndice: Extrato de o Mundo como vontade e idéia, de Schopenhauer. In: FREUD, Sigmund. O e go e o id e outros trabalhos (1923-1925). Rio de Janeiro: Imago, 1996, vol. XIX.

FREUD, Sigmund. Inibições, sintomas e ansiedade (1926 [1925]). In: FREUD, Sigmund. Um estudo autobiográfico, inibições, sintomas e ansiedade, análise leiga e outros trabalhos (19251926). Rio de Janeiro: Imago, 1996, vol. XX.

FREUD, Sigmund. Projeto para uma psicologia científica (1950[1895]). In: FREUD, Sigmund. Publicações pré-psicanalíticas e esboços inéditos (1886-1889). Rio de Janeiro: Imago, 1996, vol. I.

SIMMEL, Georg. As grandes cidades e a vida do espírito. MANA, 2005, vol. 11, n. 2, p. 577591, 2005. Disponível em: https://www.scielo.br/pdf/mana/v11n2/27459.pdf

GIDDENS, Anthony. A transformação da intimidade. São Paulo: Editora Unesp, 1993.

GUIMARÃES ROSA, João. Manuelzão e Miguilim. São Paulo: Global, 2019.

HUGO, Victor. O ogro da Rússia. São Paulo: Companhia das Letrinhas, 2012.

KAZANTZÁKIS, Nikos. Ascese: Salvatores Dei. São Paulo: Grua, 2017.

LEVI, Primo. A trégua. São Paulo: Companhia das Letras, 2010.

LITTLE, Margaret. Sobre a unidade básica (indiferenciação primária total). In: KOHON, Gregorio (Org.). A escola britânica de psicanálise. The Middle Group. A tradição independente. Porto Alegre: Artes Médicas, 1994.

MANN, Thomas. A morte em Veneza. São Paulo: Companhia das Letras, 2015.

PRADO, Adélia. Quero minha mãe. Rio de Janeiro/São Paulo: Record, 2005.

ROBINSON, Kim Stanley. The Coronavirus is rewriting our imaginations. The New Yorker, May 1, 2020. Acesso em: https://www.newyorker.com/culture/annals-of-inquiry/thecoronavirus-and-our-future.

\footnotetext{
${ }^{10}$ A referência aqui é Kazantzákis (2017, p. 46).
} 
WEBER, Max. Rejeições religiosas do mundo e suas direções. 5. ed. Ensaios de Sociologia. Rio de Janeiro: LTC, 2010.

WILLIAMS, Raymond. The Long Revolution. Wales: Parthian, 2011.

WILLIAMS. Raymond. Cultura e sociedade: 1780-1950. São Paulo: Editora Nacional, 1969.

WINNICOTT, Donald. Agressão e suas raízes. In: WINNICOTT, Donald. Privação e delinquência. 3. ed. São Paulo: Martins Fonte, 1999.

WINNICOTT, Donald. Assistência residencial como terapia. In: WINNICOTT, Donald. Privação e delinquência. 3. ed. São Paulo: Martins Fonte, 1999.

WINNICOTT, Donald. De novo em casa. In: WINNICOTT, Donald. Privação e delinquência. 3. ed. São Paulo: Martins Fonte, 1999.

WINNICOTT, Donald. O desenvolvimento da capacidade de envolvimento (1963). In: WINNICOTT, Donald. Privação e delinquência. 3. ed. São Paulo: Martins Fonte, 1999.

WINNICOTT, Donald. Objetos transicionais e fenômenos transicionais. In: WINNICOTT, Donald. $O$ brincar e a realidade. Rio de Janeiro: Imago, 1975.

\section{Sobre o autor}

Alexandro Henrique Paixão tem graduação em Ciências Sociais (UNESP - Campus Marília), mestrado e doutorado em Sociologia (USP), pós-doutorado em Teoria e História Literária (UNICAMP), Especialização em Saúde Mental e Psicoterapias Psicanalíticas (CEFAS), é Membro Filiado da Sociedade Brasileira de Psicanálise de São Paulo (SBPSP), coordenador do Laboratório de Estudos de Cultura, Educação, História, Sociologia e Psicanálise (LECHESP) e professor de Sociologia, com os seguintes temas de pesquisa: teorias sociológicas, literárias e psicanalíticas, sobreviventes de guerra, Raymond Williams e Donald Winnicott.

E-mail: ahpaixao@unicamp.br. 